\title{
As formas verbais do galego actual: unha achega desde a percepción
}

\author{
The verbal forms in current Galician: an approach \\ from the Theory of Perception \\ ÁngEl Soto García (UNED) \\ ninoflorio@galicia.com \\ Recibido: noviembre de 2014. Aceptado: enero de 2015
}

\begin{abstract}
Resumo: A gramática perceptiva fundaméntase na consideración da linguaxe como un sexto sentido. A percepción do mundo como animais que somos realízase pola vista, fundamentalmente; e iso impregna a linguaxe e todas as súas diversas dimensións funcionais e categoriais. O problema da lingüística a través da súa historia reside, aínda hoxe en día, en que a explicación aos fenómenos da linguaxe son expresados coa propia linguaxe. Será a Gestalt e as súas teorías, sobre todo a lei de fondo e figura, a que nos confira valiosas ferramentas para resolver tal paradoxo. Veremos, nomeadamente, como algunhas diferenzas e analoxías do uso dos tempos verbais en galego ben poden seren explicadas desde esta teoría. Ditas explicacións enmárcanse dentro dunha lingüística de pensamento.
\end{abstract}

Palabras clave: Gestalt, tempo verbal, perífrase, lei fondo-figura, percepción actual, percepción futura, percepción remota.

Resumen: La gramática perceptiva se fundamenta en la consideración del lenguaje como un sexto sentido. La percepción del mundo como animales que somos se realiza por la vista, fundamentalmente; y ello impregna el lenguaje $\mathrm{y}$ todas sus diversas dimensiones funcionales y categoriales. El problema de la lingüística a través de su historia reside, aún hoy en día, en que la explicación a los fenómenos del lenguaje son expresados con el propio lenguaje. Será la Gestalt y sus teorías, sobre todo la ley de fondo y figura, la que nos confiera valiosas herramientas para resolver tal paradoja. Veremos, asimismo, cómo algunas diferencias y analogías de las diversas lenguas pueden ser explicadas desde esta teoría. Estas explicaciones se enmarcan dentro de una lingüística del pensamiento.

Palabras clave: Gestalt, tiempo verbal, perífrasis, ley fondo-figura, percepción actual, percepción futura, percepción remota. 


\section{INTRODUCCIÓN}

Resulta até certo punto inevitábel, á hora de falar do verbo galego, non facermos similitudes con outros paradigmas verbais das diversas linguas da mesma descendencia, que con máis ou menos substancia se asemellan a nosa fala e comparten connosco un léxico e unha gramática case comúns. Mais nós cremos, e así o desenrolaremos neste estudo, que pretende ser ante todo obxectivo co contexto que nos circunda, que isto non acontece así cando se fala dos verbos e as súas formas, xa que as diferenzas vanse incrementando co paso do tempo. Queremos, máis que todo, mostrar como transformamos a percepción do mundo nun sistema lingüístico complexo.

Partiremos para afondar neste asunto desde a perspectiva perceptiva como abordaxe natural desde a que chegar ao nivel do discurso, que vén sendo tan estudado hoxe en día desde a gramática discursiva e a pragmática. Teremos en conta como fío condutor as diversas teorías da Lingüística Cognitiva, pero sentando as bases desde a Gramática Liminar que desde a universidade de Valencia se propuxo na década dos oitenta.

Sexa como for, a nosa meta só pretende unha explicación de que formas están a ser usadas e por que do seu uso. Afastarémonos na medida do posíbel do estudo do verbo segundo o seu semantismo, se ben faremos uso del nas explicacións que se precisar. O que aquí nos interesa é a súa temporalidade, o seu dinamismo, a súa aspectualidade, e todos aqueles trazos que teñan que ver coa percepción da estaticidade ou do decorrer no tempo.

Sobre isto, Ángel López García $(2005,145)$ precisa o seguinte,

Aquí lo que se halla en juego es un dinamismo orientativo que los gramáticos convienen en llamar tiempo. Si algo distingue al ser humano de los animales es que resulta capaz de desarrollar imágenes mentales que no están ligadas a la situación actual, es decir, mundo mentales que le recuerdan el pasado o con los que imagina el futuro. Por eso, afirmar que el ser humano es una animal que habla, un animal que piensa o un ser histórico viene a ser casi lo mismo. Evidentemente estos mundos serán pasados o futuros por relación a un punto de referencia...En el lenguaje el punto de referencia de la orientación es el mismo en todas las lenguas: el momento del habla. No obstante, frente a lo que ocurre en los calendarios, en el lenguaje dicho punto de refencia se va modificando conforme distintos hablantes van tomando el turno.

Dada esta coincidencia entre las distintas lenguas, surge la pregunta de por qué difieren tanto sus sistemas verbales de tiempo.

Veremos, nomeadamente, que o uso das formas verbais galegas se basea tanto ou máis na percepción que os falantes teñen do mundo que no feito do decorrer do e no tempo dese mundo. De aquí que a aspectualidade teña un papel importante ou destacado sobre a temporalidade ou a modalidade. Certo é que non podemos desvincular a percepción dunha acción, dun proceso, do tempo no que este se ten producido; tampouco a nosa posición fronte ao 
modo pode ser esquecida ou non tratada neste estudo, presentaríase imposíbel, sobre todo cando, de maneira importante, incide, como veremos, nas formas futuras que son usadas habitualmente. Por todo isto, formulemos, antes de nada, o que desde a percepción (López García 2005, 148) entendemos destas tres variábeis:

1. El tiempo (al igual que los demostrativos) orienta la oración por relación al momento en que el hablante la enuncia. El tiempo verbal sitúa la oración respecto al AHORA, respecto al momento del yo hablante $(. .$.

2. El modo (al igual que los posesivos) orienta la oración con relación a las personas del diálogo entre las que interactúa. El modo verbal sitúa la oración respecto a las PERSONAS YO-TÚ (...)

3. El aspecto (al igual que los relativos) orienta la oración no sólo en relación con el yo sino también respecto del mundo exterior en el que dicho yo está integrado. El punto de referencia del aspeccto verbal es, pues, el AQUI del habla.

\section{A GRAMÁTICA LIMINAR: LINGUAXE E VISIÓN}

A Gramática Liminar é unha teoría da linguaxe cuxas teses, difundidas desde a Universidade de Valencia, aparecen publicadas por primeira vez no libro do profesor Ángel López García, Para una Gramática Liminar (1980). É, xa que logo, unha visión que hoxe se pode entender dentro das teorías da gramática cognitiva, como consecuencia da crise da gramática xerativa daqueles tempos. A gramática liminar, en contra das formulacións algorítmicas matemáticas da escola xerativista, fundamenta as súas formulacións na percepción humana, é dicir, non concibe a linguaxe fóra do contexto no que se produce; é, sobre de todo, unha gramática perceptiva. Vexamos as palabras do propio López García $(2006,2)$ :

Si las lenguas son formas de percibir el mundo, parecidas, aunque no equivalentes, a percepciones que se alcanzan mediante los sentidos, y en particular el de la vista, no parece insensato plantear la hipótesis de que existe un nivel de conceptualización en el que las leyes que rigen la imagen verbal del mundo transmitida por una escena oracional y las leyes que rigen la imagen visual de este mismo fragmento de lo real son, como mínimo, análogas.

Enténdese neste suposto da gramática liminar que a metalinguaxe gramatical é unha derivación diacrónica da metalinguaxe natural, da nosa percepción sobre o mundo. Ao ser humano chégalle o mundo a través dos sentidos, do mesmo xeito que aos demais seres vivos, pero se algo, entre outros, nos fai diferentes destes últimos é a linguaxe. Unha mensaxe que nos vén dada no contexto vivencial podémola sentir desde o tacto, o olfacto, o ouvido, o gusto, a vista, e, 
certamente, desde a linguaxe. Téñase en conta que tamén a linguaxe pode ser física, oral e escrita, do mesmo xeito que os demais sentidos. Son todos eles representacións que nós facemos do mundo; a nosa mente cáptao e vólveo presentar simbolicamente.

Non sería certo do todo afirmar que a linguaxe é unha prolongación evolutiva do sentido do ouvido e da vista; pero as formas de percibir lingüisticamente o mundo son moi parecidas a como o captamos coa visión. Así, desde a gramática liminar enténdese que a linguaxe e a visión camiñan de forma paralela, reforzándose mutuamente, incluso substituíndose. Se queremos que alguén, nun contexto dado de, por exemplo, comida familiar, nos pase o saleiro, ben podemos referirnos a iso mediante a linguaxe, «pásame o sal, por favor!», ou ben sinalando o saleiro con algún xesto concreto.

O importante, segundo esta concepción do lingüístico, é que na linguaxe, cando nos fixamos nun elemento, estamos a salientalo sobre outros que o delimitan como consciencia metalingüística deste. Por tanto, a consideración simultánea da linguaxe e a metalinguaxe é o trazo diferencial desta gramática perceptiva: os feitos da linguaxe xunto coa consciencia que temos deles. Debido a esta fronteira marcada entre os dous termos, falamos do liminar; será, xa que logo, perceptiva, como dixemos anteriormente, pola captación que facemos do mundo.

Consideramos, deste xeito, a figura como aquel obxecto, acción ou fenómeno que percibimos en primeiro termo, mentres que of fondo é o que percibimos nun segundo plano; deste xeito, podemos estudar a linguaxe en toda a súa xeneralidade baixo esta distinción entre figura/fondo. Vexamos algún exemplo desde a vivencia: se nos encontramos a pasear por unha rúa calquera dunha cidade calquera podemos, por que non, pararnos fronte a unha vitrina dalgún negocio que nos chame a atención. Se o que nos fixo parar fronte ao cristal foi un traxe ou un vestido concreto, estaremos a facer del a figura da nosa percepción fronte ao resto da vitrina, é dicir, o fondo. Ora ben, o noso interese pódese centrar non nunha peza concreta, senón no tipo de roupa que venden no establecemento. A figura mudaría agora no nivel da percepción xa que enfocaremos a nosa mirada e toda a nosa atención na xeneralidade do exposto, é dicir, nas outras pezas. A figura, agora, será outra diferente. O importante será, entón, aquela figura que predomina por mor da nosa atención sobre ela.

$\mathrm{Na}$ linguaxe parece que sucede algo parello. A percepción sensorial supón unha recreación ou representación do mundo percibido. A oración verbalizada que corresponde á realidade dese mundo non é o mundo, pero ben se lle asemella. A gran diferenza entre mundo percibido e mundo representado a través da linguaxe radica na arbitrariedade deste último. Nunha relación coas demais especies podemos dicir que todos nos relacionamos mediante o gusto, o olfacto e o tacto, só as relacións sociais, tipicamente, aínda que non unicamente humanas, se alicerzan na mirada e na linguaxe. Isto é importante por canto as investigacións científicas están a probar a relación entre un sentido e outro, é dicir, entre a conexión neuronal da linguaxe e a visión. 


\section{O VERBO E A PERCEPCIÓN}

\subsection{As formas da percepción actual}

Sería inexacto dicir que o presente temporal no galego exprésase tan só polos tempos do presente do indicativo e do subxuntivo do noso paradigma verbal. A moi poucos se lles escapa esta constatación.

A percepción cognitiva do actual, do que nós percibimos dentro do noso rango do «que nos está a suceder» ou do «que nos está a afectar directamente na realidade percibida» pódese expresar en galego por medio de diversos valores das formas verbais do noso paradigma.

O común é que o galegofalante utilice o tempo presente para actualizar o enunciado. É por isto que este tempo organiza lingüisticamente o que está a suceder no momento da fala, é dicir que o enunciado e a enunciación son coincidentes; porén non sempre é así xa que son moitos os exemplos onde o presente non cumpre esta coincidencia: presente histórico (narrativo), presente permanente (atemporal), e presente con valor de futuro. Alén destes valores temporais, esta mesma forma verbal presenta uns valores aspectuais e modais concretos segundo as relacións temporais nos que se percibe: habitual, de duración, imperativo, condicional e intensificador no indicativo; desiderativo, de posibilidade e imperativo no subxuntivo.

É curioso que os galegos, entre outros falantes de linguas románicas, teñan uns tempos verbais nos que a diferenza menos salientábel sexa a temporal, pois pasa a un segundo nivel distintivo, adxudicando, en certos casos, como se verá cando falemos do futuro, unha maior prominencia aos valores de modalidade. Isto ben pode ser explicado desde o punto que estamos a defender: o único tempo real, desde a nosa percepción do mundo, é o tempo actual, comprendido sempre desde unha perspectiva de continuidade, que alcanzará o pasado como tempo lineal de pasado lembrado, que trae a memoria algo ou a alguén, onde a acción se percibe dentro dunha continuidade temporal e espacial do acto concreto nun espazo definido, podendo, de ser o caso, dar indicacións precisas dos feitos acaecidos:

\section{(1) (Lembro que) aquel mesmo día fun á casa do xastre, \\ (2) (Lembro que) chovía a mares;}

ou de pasado evocado, que fai pensar en algo ou alguén, e onde esa continuidade é anulada polo valor aspectual de repetición, que non habitualidade, nunha franxa espazo temporal abstracta que produce que o acto sexa percibido fóra dun tempo e espazo temporal axeitadamente definido:

\section{(3) Cando pequeno, teño ido á casa da miña avoa.}

No caso do futuro teremos tantas realidades presentes coma intencións, decisións ou desexos contemplemos. Será, xa que logo, un futuro de modalidade: 
(4) Irás á casa do Xoán.

(5) Espero non vaias caer.

$\mathrm{O}$ resto queda rexistrado dentro da franxa do presente, sexa este presente (perspectiva actual) propiamente dito, ou anterior, posterior e atemporal ou mesmo permanente.

A percepción do presente non destaca pola súa complexidade de uso, mais si pola percepción do mundo que nos ofrece, como instrumento modificador da lingua. Todo o que se percibe como actual, coincidente no enunciado e na enunciación, como dixemos, materialízase na forma do presente de indicativo:

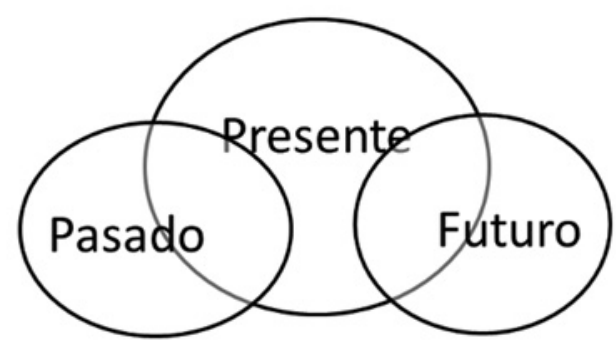

(6) - De que ris? -pregunteille.

- Río de ti.

Podemos observar, desde o estudo fondo -figura que estamos a tratar neste traballo, que esta formalización do presente sitúase da seguinte maneira:

(7) —De que ris/estás a rir? -pregunteille.

- Ríol estou a rir de ti.

Aquí o fondo é o tempo cronolóxico desde a perspectiva do presente percibido, mentres que como figura resalta o seu aspecto imperfectivo.

Entendemos para este caso e para as demais formas verbais a tratar que o tempo vén sendo unha formalización do contexto no que se substancia o predicado, que ben pode definirse mediante complementos diversos, véxase os adverbiais, nomes temporais, ou pola propia morfoloxía do verbo. Se isto non fose así, non poderiamos ter formas verbais do presente en canto a aspectos pasados ou futuros, como veremos. A nosa defensa, polo tanto, vai no camiño da secundariedade do accidente temporal nas formas verbais fronte a outros aspectos salientábeis como poden ser a imperfectividade, a anterioridade, a repetición, etc.

Destaca en galego, xa que logo, que cando a acción é imperfectiva, referímonos ao seu proceso interno; así, no presente pódese utilizar de forma invariábel tanto o tempo verbal do indicativo canto a perífrase estar $a+$ inf. 
Porén, non sempre cómpre a «puntualidade» temporal do feito presente xa que no pasado e no futuro, como xa apuntabamos anteriormente, tamén se impón o uso do presente cando actualizamos os feitos e os percibimos dentro do noso espazo vital, fóra da rememorización do anterior, lembranza ou evocación, ou da proxección posterior. Estamos a falar da percepción actual anterior, da percepción actual posterior e da percepción actual permanente.

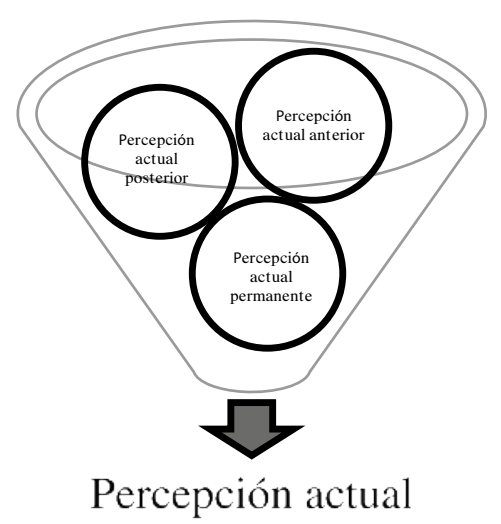

\subsubsection{A percepción actual anterior}

Esta percíbese como aquel tempo que recolle os feitos que nos están a afectar desde o pasado, máis ou menos afastado, até o presente actual, podendo, en certo modo, traspasar a raia fronteiriza que separa o decorrer do presente coas expectativas ou os desexos cara o futuro, xa que de certo é imposíbel afirmar unha continuidade real de dito feito. $\mathrm{O}$ presente virá usado en oracións con carácter habitual (8) e durativo (9) e (10) cando sexan percibidas deste xeito; é dicir, amose os valores aspectuais propios do tempo presente e do pasado:

(8) Cada día xorden máis problemas dos que pensamos.

(9) Como peixe desde que era ben cativo.

(10) Canto desde que era ben cativo.

- Fondo: toda a perspectiva temporal de percepción obxectiva do pasado, presente e futuro.

- Figura: aspecto habitual e durativo do feito no tempo.

A particularidade verbal galega ten a súa maior diferenza, ao respecto das linguas limítrofes ao seu territorio de uso, en que produce lingüisticamente o 
seu pasado estritamente temporal cun só tempo verbal: o pretérito do indicativo. Deste xeito non se precisa que o feito teña sucedido dentro dun tempo remoto, tamén pode ser inmediato. Dado o seu valor de aspecto perfectivo, que entendemos explicado desde a temporalidade no pasado, percíbese dentro do percorrido temporal da actualidade xa pasada, sexa máis ou menos veciña ao noso estado presente ou á enunciación da proposición. Por isto, en galego adoitamos dicir,

(10) Esta mañá comprei un calzado novo.

(11) Esta mañá xoguei ás bolas.

Se o verbo for transitivo,

(12) Esta mañá [comprei un calzado novo].

- Fondo: perspectiva temporal do presente anterior.

- Figura: aspecto puntual; situación instantánea sen percepción durativa.

Mentres que se for intransitivo:

(13) No pasado martes finou logo dun tempo enfermo.

- Fondo: perspectiva temporal do presente anterior.

- Figura: aspecto puntual: situación instantánea sen percepción durativa.

(14) Esta mañá [xoguei] ás bolas = Esta mañá [estiven a xogar] ás bolas.

- Fondo: perspectiva temporal do presente anterior.

- Figura: aspecto durativo: percepción de prolongación no tempo.

Nótese a diferenza con:

(15) Cando neno xoguei ás bolas;

que non:

(16) *Cando neno estiven a xogar ás bolas

onde a figura contén o aspecto puntual, e non a durativa do caso anterior. Se ben debemos ter en conta que isto sucede cos verbos cuxo semantismo así o permi- 
te, non sería o caso de verbos do tipo saír, estourar, gritar,... onde a perífrase reflicte a iteración do acto:

(17) Esta maná saín da casa ás oito en punto.

mais non,

(18) *Esta maña estiven a saír da casa as oito en punto.

Veremos máis adiante que a figura desta forma verbal troca cando o fan os complementos predicativos contextuais.

No caso de se tratar de accións coincidentes, teremos:

(19) Esta mañá [compraba] un calzado novo cando ti chegaches = Esta mañá [estaba a comprar] un calzado novo cando ti chegaches.

- Fondo: perspectiva temporal do presente anterior.

- Figura: aspecto imperfecto: percepción interna da oración principal (estaba a comprar).

Ora ben, cando queremos que as nosas proposicións se inactualicen (estean fóra do noso campo de visión de percorrido do feito e pasen a facer parte do recordo), por razóns pragmáticas ou estilísticas, ou porque queremos indicar un aspecto a máis ao perfectivo, podemos recorrer tanto ao indefinido para a lembranza canto á perífrase verbal ter + participio para a evocación, dado o seu valor reiterativo puntual (percepción remota), que non debemos confundir coas verdadeiras formas temporais compostas, formadas co mesmo paradigma verbal, e que están de feito na fronteira da percepción actual. Analizaremos isto último cando falemos da posterioridade.

Outra referencia que é de obriga facer, corresponde a forma do antepretérito «fixera». Esta sinala no tempo unha acción anterior a outra que xa pasou; mais non por isto deixa de estar actualizada desde a nosa percepción do feito:

(20) Cando chegaches, xa eu comera.

cuxa súa percepción, se ben a aspectualidade principal sexa a de anterioridade a un feito xa pasado, coincide, nalgúns casos, coa do pasado perfectivo da forma «comín».

(21) Cando chegaches xa eu comera/comín. 
- Fondo: perspectiva temporal do presente anterior + aspecto puntual.

- Figura: comera: relación temporal de anterioridade; comín: aspectualidade perfectiva de acción rematada.

\subsubsection{A percepción actual posterior}

Constrúese co paradigma formal do tempo presente cando proxecta os valores modais propios do futuro.

- Fondo: toda a perspectiva temporal de percepción obxectiva do pasado, presente e futuro.

- Figura: os valores modais posibles do futuro.

Entón, poderemos atopalo en:

$\sqrt{ }$ Modalidade imperativa, con consecución do acto no presente posterior:

(22) Deixa todo o que estás a facer e vénte comigo.

$\sqrt{ }$ En oracións interrogativas, onde se fai unha solicitude a unha terceira persoa ou a un mesmo, do tipo:

\section{(23) Voume cedo ou fico un anaco máis?}

$\sqrt{ }$ Con calquera tipo de marcador adverbial, o cal resolva como posterior, mais con carácter de actualidade, a consecución do acto concreto, considerado este como un feito real que acontecerá de certo:

(24) O vindeiro martes chamo a Marta.

$\sqrt{ }$ Como valor narrativo do presente, que localiza accións acaecidas no pasado, pero que se perciben como actuais por seren feitos históricos que permanecen na memoria colectiva, pudendo ir máis aló deste, ate o futuro:

(25) Rosalía escribe as súas mellores obras tanto en galego como en castelán.

\subsubsection{A percepción actual anterior condicionada}

Fai referencia a aquela condición que non se tivo realizado ou sexa imposíbel realizala no presente. Estamos a falar dunha percepción irreal condicionada. 
$\sqrt{ }$ Modalidade condicionada irreal, imposíbel de que aconteza na posterioridade:

(26) Se tiveses sido bo ${ }^{1}$, teríache mercado unha boa chea de lambetadas.

Onde o Fondo é a perspectiva temporal anterior; e a Figura, a condición xa irrealizábel.

\subsubsection{A percepción actual posterior condicionada}

É complexa demais por canto reúne formas verbais diversas con valores, a súa vez, tamén diversos, nunha temporalidade presente ou futura. Xa que nós defendemos, ao longo deste traballo, que os feitos futuros ou hipotéticos non deixan de ser intencións reais ou probabilísticas percibidas desde a actualidade das nosas vivencias, entendemos que o punto de referencia temporal dunha condición da que non coñecemos a súa conclusión non deixa senón de pertencer a esfera da actualidade, é dicir, pertence ao presente.

1 Á vista dos datos que recollemos de fontes reais, é dicir, da riqueza lexical que a literatura e a escritura xornalística nos ofrecen, non podemos negar a existencia dos tempos compostos no galego actual, que como se poderá observar non son coincidentes coa totalidade do paradigma dos tempos en español, así como tampouco dos seus referentes nun idioma irmán, histórica e xeograficamente, como é o portugués. O condicional composto denota un tempo anterior a un condicional, é dicir, a un pospretérito. É outro dos casos nos que a anterioridade unida a outros aspectos, como a condición imposible, demostra a obrigatoriedade das formas compostas, complementarias ás súas formas simples: Supoñian [pretérito] que cando chegase [ $\leftarrow$ post] o inverno, terminaría [Łante] a guerra. (Bosque et al., 2009) Observamos a distinta temporalidade que significa a súa forma simple: Supoñían [pretérito] que cando chegara [Łpost] o inverno, remataría [«simul] a guerra.

(1) No caso dunha resposta favorábel teriamos adiantado moito no camiño dá obtención de bos animais de carne, a partires sempre dunha estirpe, suficientemente rústica e resistente. (Caamaño, 1981).

O condicional composto utilízase nas apódoses dos períodos irreais introducidos en español polo pretérito imperfecto ou o pretérito pluscuamperfecto de subxuntivo. En galego as condicionais de tipo III ou irreais usan este último tempo en modo subxuntivo:

(2) Pero moitas veces penso non que tería sido eu se me tivese marchado e andase polo mundo, ou se me tivese decidido a traballar nunha cousa. (de Toro, 1993).

(3) Ese prezo tería tido algunha vantaxe se Fraga tivese traído ou que se lle supoñía: un bo gobernar. (Rúa, 1996).

(4) Se A tivese sucedido, aínda cando non sucedeu de feito, entón tamén tería sucedido B. (Carreira, 1998).

(5) Se ou Partido Popular tivese chamado a votar non, a participación seguramente tería superado ou 50\% do censo e hoxe estariamos levantando acta dun gran triunfo do PSOE en tanto que Partido Rexionalista Andaluz. (A Nosa Terra, 2007).

(6) Se tivésemos ido de fronte non o teriamos conseguido. (Veiga, 2003).

Como variante obsérvase a obrigatoriedade do composto rexido por expresións do tipo: quen me dera ; oxalá; etc., onde o emisor laméntase dun feito non realizado:

(7) Quen me dera que tivese aprobado! Non tería que estudar de novo. 
$\sqrt{ }$ Modalidade condicionada posíbel, cando se fai referencia a unha actualidade posterior posíbel:

(27) Se es bo, mercareiche / quizais che merque unha boa chea de lambetadas.

Neste caso, o fondo corresponde co presente ampliado xa que, de non facerse referencia explícita, non se coñece o momento da realización da condicional. Como observamos, o contexto continua a ser a cuestión máis importante á hora de temporizar a formalidade verbal.

A figura é a condición realizábel, neste caso, nun tempo indeterminado; mais que, como tal, é dicir, como intención, sempre estará dentro do tempo actual ou futuro.

Modalidade condicionada hipotética, cando se fai referencia a unha actualidade posterior improbábel:

(28) Se foses bo, mercaríache unha boa chea de lambetadas.

Aquí o fondo correlaciona todo o espazo temporal con proxección futura. A percepción é atemporal; podemos entendelo mellor con estoutro exemplo:

(29) Se estudases, terías un mellor traballo.

A figura é a hipótese, é o que pretendemos con esta expresión como acto de ilocución propio.

\subsubsection{A percepción actual permanente ou atemporal}

Refírese a feitos que percibimos como iguais, sen cambio algún, no decorrer do tempo:

(30) Bo mariñeiro sempre naufraga.

(31) O sol é o astro rei.

Neste caso o fondo e a figura coinciden por canto que a proxección do tempo no percorrido da expresión é, ademais, a percepción como figura.

\subsubsection{A percepción actual futura}

Como vimos afirmando, ten un compoñente altamente modal que se ten estudado nas diferentes gramáticas dun punto esencialmente formal na súa clasificación, máis hoxe hai traballos (Escandell, 2010) onde a perspectiva é ben distinta. Estamos a falar da evidencialidade do futuro como feito que resolve a carga específica modal e temporal das formais verbais futuras:

El futuro es, sin duda, un tiempo problemático. Lo es, por supuesto, desde el punto de vista vital, ya que a los humanos no nos es dado conocer con antelación los 
acontecimientos que ocurrirán en el porvenir; pero lo es, igualmente, desde el punto de vista gramatical, ya que el tiempo verbal futuro presenta interlingüísticamente propiedades, cuando menos, sorprendentes. (Escandell, 2010, pág. 10).

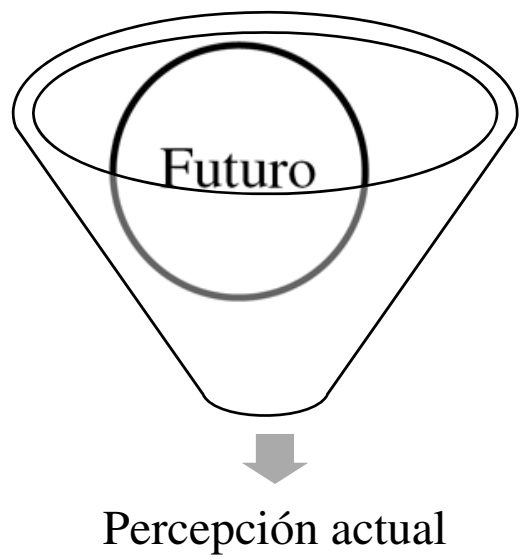

Certo é que o futuro pode quedar explicado desde a temporalidade como acción posterior ao momento da enunciación, que vai ser un futuro senón algo que deberá, ou non, acaecer? Porén, cremos que este non é senón unha consideración que non se lle escapa a ninguén, lingüista ou non. Deberemos ir mais aló. Queremos dicir con isto que o uso do tempo futuro contén unha percepción das referencias do mundo e das accións que nel acontecen que non son resoltas coa simple temporalidade. Vén sendo a nosa postura fronte a un mundo que non coñecemos, en tal caso imaxinábel, de aí todos os seus distintos valores. Sexa como for, o futuro, para nós, non deixa de ser unha forma actual xa que o mundo que se describe con el non é senón unha procura dos desexos ou das intencións que temos desde o noso presente actual; será, por tanto, un futuro desde o enfoque modal. Distinguiremos as seguintes formas cos seus valores precisos que se materializan no futuro simple do indicativo:

\section{$\sqrt{ }$ Valor temporal prospectivo:}

\section{(32) Mañá comerei peixe, xa terei tempo de meterlle unha boa costeleta!}

Podemos, mesmamente, observar como a perífrase $i r+$ infinitivo introduce un valor engadido de intencionalidade:

(33) Mañá vou comer peixe, xa terei tempo de meterlle unha boa costeleta!

onde o fondo, en ambos os dous casos, corresponde coa perspectiva temporal do futuro; e a figura, coa modalidade propia da expresión enunciada: futuro desde a perspectiva modal dos feitos posibles, intencionais.

Cabe pensar que esta segunda forma perifrástica sexa actualmente a máis usada no discurso, isto indicaría que a percepción que nós temos da realidade 
posterior é máis intencional que real. Como exemplo temos que, cando facemos unha pregunta con resolución posterior, abofé que usamos a perífrase:

(34) Que vas facer na próxima semana?

Outros valores son:

$\sqrt{ }$ Valor de probabilidade:

(35) Estaredes ben desfeitos despois de tanto camiñar!

$\sqrt{ }$ Valor imperativo:

(36) Farás si ou si o que che estou a dicir.

$\sqrt{ }$ Valor aproximativo:

(37) Terá dos millóns aforrados. Non che gasta un peso!

$\sqrt{ }$ Intensificador negativo:

(38) Serás pillabán!

Chegados a este punto, non queda outra que falarmos das formas compostas do futuro, xa que con el acontece a percepción contextual de probabilidade ou intencionalidade (figura) nun tempo delimitado ou non (fondo) que máis se ven usando na escrita:

(39) Segundo as últimas informacións que nos chegan, ao regreso das vacacións estivais xa terán rematado ${ }^{2}$ os traballos de rehabilitación das vivendas afectadas polo furacán.

(40) Para cando veñas a buscarme, xa terei estudado os temas de física.

2 O futuro perfecto é unha forma verbal relativa. A súa referencia denota un momento posterior ao feito da anunciación que, á súa vez é anterior a outra acción, polo que nos vemos na necesidade de utilizar unha forma verbal composta que denote dita anterioridade: Para cando lles chegue esta carta xa terán feito a malla do trigo. (Maiz, 1994) Mentres, os seus ocasionais ou habituais contertulios terán feito o máis firme propósito de esquecerse de vostede. (Prego, 1994). Como podemos observar, o seu valor temporal é similar a aquel que se infire no seguinte exemplo do español: Suponen [presente] que cuando llegue [ $\leftarrow$ post] el invierno, terminaría [ $\leftarrow$ ante] la guerra.

As gramáticas ao uso do galego introducen que a anterioridade no futuro expresarase en galego co pretérito do indicativo que indica unha acción xa concluída antes do momento da enunciación:

(1) Cando volvas, seguro que xa fixen ou xantar.

Porén, vemos que si para a primeira das proposicións (1) o valor temporal, non así o aspectual (forza ilocutiva), non se ve afectado co cambio proposto:

(2) Para cando lles chegue esta carta xa fixeron a malla do trigo.

Para a segunda (2) o sentido, e polo tanto o significado temporal pleno da frase, troca por completo, trasladando a acción cara ao pasado ou futuro, pero neutralizando a lectura estrita de simultaneidade futura: 
Un caso especial, que podería ser estudado nos dous puntos anteriores, é a forma verbal teña feito ${ }^{3}$, no seu valor temporal, chamado subxuntivo retrospectivo e prospectivo, máis non entraremos no seu estudo perceptivo pola peculiaridade temporal do subxuntivo que xa sinalamos anteriormente. Porén, apuntaremos, ao pé, a peculiaridade deste tempo composto que defendemos.

\subsection{As formas da percepción remota}

É de grande importancia para o galego a distribución complementaria do pretérito fun, como tempo verbal e de teño ido, como perífrase, así como a súa disposición fronte a o copretérito ía, que dentro deles se pode encaixar como acción paralela.

Atopamos, deste xeito, unha diferenza consubstancial no que respecta á aspectualidade nas diferentes formas:
(41) Cando pequeno fun á casa do Xoán.
(42) Cando pequeno ía á casa do Xoán.
(43) Cando pequeno teño ido á casa do Xoán.

(3) Mentres, os seus ocasionais ou habituais contertulios *fixeron/*farán/*fan ou máis firme propósito de esquecerse de vostede.

Temos, tamén, que o futuro de conxectura que en español se formaliza mediante o tempo composto é un bo exemplo de que a súa aspectualidade non é sinónimo, en galego, de formas reiterativas ou habituais: Non me chamou, sairronlle mal os exames, ten o seu paralelo no galego actual con exemplos do tipo:

(4) Deus, unha declaración de amor tan repetida, que tantos mozos lles terán feito a tantas mozas tantas veces en tantos lugares, e eu sentín perfectamente que era única, que ía dirixida só a min e que era absolutamente sincera (Vázquez, 1997).

Atopamos exemplos na literatura e na escritura xornalística actual galega onde o uso do futuro composto faise necesario:

(5) Segundo a Dirección Xeral, haberá estudos sociolingüísticos e examinaranse as posibilidades de avanzar na implantación dá lingua, a idea é que cando ou plan estea feito xa haberá un grupo de xente que terá adquirido un compromiso. (Vixante, 2002)

Ocorre o mesmo co futuro de subxuntivo, o cal, aínda que non vén sendo utilizado na oralidade, déixase ver na literatura, nun rexistro culto, exclusiva de niveis moi elevados, en exemplos do tipo:

(6) Tende coidado e non a tomedes en grandes doses nin durante longos períodos de tempo que, nese caso, quen a tiver bebido poñerase a soñar coa liberdade e sentirá decontino ganas de voar. (Moure, 2007)

3 (1) Témonos principalmente esforzado, anque ben difícil é que ou teñamos conquerido, en achar o equilibrio entre a mera divulgación pra quen carece de información política teórica, e o profundamente ideolóxico, forzadamente esquemático, que puidese mesmo axudar a persoas formadas nese senso e interesadas nun máis... (Rivas, 1997)

(2) Cando se teñan rematado os monumentos arquitectónicos, agarda, tamén, a urbe medieval de Tui, dificilmente para ou 2001, pola rivalidade de Úbeda e Baeza, que outra opción pode brindar Galicia? (Abuin de Tembra, 2000) 
Fronte á perfectividade e ao dinamismo perceptivo da forma fun, na que localizamos o feito en si (espazo e tempo), atopamos a continuidade no tempo da forma ía que se contrapón a forma composta teño ido, a cal non actualiza o feito, poñéndoo no recordo absoluto, desde a percepción remota, e como un feito de experiencia desde a percepción «nubolosa» dun recordo sen espazo e tempo definido. Asemade, mentres que a segunda das formas (42) vense usando para aumentar o valor continuo da acción, non sucede da mesma maneira no uso da primeira (41) das formas indicadas. Deste xeito adóitase escoitar,

(44) Cando pequenos andabamos sempre ás agachadas.

Porén:

(45) Cando pequenos temos andado algunha vez ás agachadas.

(46) *Cando pequenos temos andado sempre ás agachadas.

o que reforza a tese do uso invariábel dunha ou outra forma verbal segundo teñamos unha percepción ou outra do feito comunicado.

Como podemos observar, cando o feito é experiencial e continuo adoitamos facer uso das formas remotas de evocación da perífrase verbal. Se, pola contra, o aspecto é habitual, facemos uso do imperfecto, tamén evocador nestes casos; mentres que, se a diferenza está sobre a base da aspectualidade perfectiva/ imperfectiva, percibímolo como un tempo que forma parte da nosa actualidade e non pasou ao espazo do recordo remoto, facendo uso do indefinido e do imperfecto para marcar a diferenza aspectual.

Así como a forma verbal se afasta do presente, o proceso dinámico (perfectivo/imperfectivo) do aspecto verbal vaise diluíndo para dar como resultado un proceso distinto, onde o importante non é se a acción se percibe dentro do seu rango interno ou externo (facía/fixen), senón que o importante pasa a ser o valor reiterativo da forma verbal dentro da franxa temporal cronolóxica. Este valor pode ser, como dixemos anteriormente, puntual/habitual. Ora ben, temos que facer certas precisións sobre isto último, é dicir: por que dicimos que a perífrase ter + participio ten carácter experiencial, mentres que o perfecto ofrece a proposición un carácter de puntualidade?

\section{(47) Cando pequeno comín na casa do Xoán.}

(48) Cando pequeno teño comido na casa do Xoán.

Existe algunha diferenza cognitiva de percepción? Soportan ambas o mesmo valor desde o punto de vista da función e da categorización? Non hai dúbida ao afirmarmos que, se ben desde a gramática, non teriamos máis que expor que, aínda que se diferencian por seren un verbo pleno fronte a unha perífrase verbal, ambas delas son soporte da función predicativa, mais parece que non ocorre o mesmo desde o uso que facemos delas, por que? Non dá a impresión que a diferenza estea no carácter [+/- perfectivo], xa que ambas se caracterizan por este aspecto. Podémonos preguntar se o aspecto que diferenza estas formas é o 
seu carácter repetitivo/ habitual, tal é como se expresa nas gramáticas usuais do galego actual. Parece que tampouco. Ninguén pode supor a primeira vista que o feito de ir a comer a casa de Xoán teña porque ser única en cantidade, na oración que estamos a analizar. Só temos que engadir á mesma algún complemento circunstancial para desfacer esta ambigüidade:

(49) Cando pequeno comín moitas veces / poucas veces na túa casa.

(50) Cando pequeno teño comido na túa casa.

E logo, facemos un uso indistinto das ditas formas verbais? Non. Defendemos, por tanto, que é unha cuestión perceptiva a que produce a distinción de ámbalas formas, que repercute no uso das mesmas: na primeira (83), o feito aproxímase a nosa vivencia desde a percepción actual, é un acto de lembranza dun acto presente que se produce no pasado desde a enunciación, fronte ao acto evocador da segunda forma (84), percibido desde a vivencia do pasado, na que se dilúe a visión da acción.

No uso da forma verbal «fixen» na seguinte oración:

(51) Hoxe fixen os traballos do colexio.

de aspecto finalizado, non atopamos unha referencia pasada no feito, xa que a nosa percepción do pasado vai máis aló dun tempo cuantificativamente curto. O mesmo ocorre na seguinte proposición:

(52) Aquel día fixen os traballos.

na que a nosa percepción é quen de ir atrás no tempo para poñernos na situación concreta do feito concreto, polo que se perde a referencia do tempo pasado, aínda que saibamos que non deixa de ser un feito afastado temporalmente. Cando dicimos:

(53) Ovidio ten estudado moito, agora non hai quen poida con el.

a nosa visión non accede á esfera do inactual desde o presente, máis ben, o acceso faise no inactual desde o pasado, por mor do seu aspecto experiencial. Así:

- Teño feito: [+ experencial] [- puntual] [+iterativo]

- Fixen: [- experencial] [+ puntual]

Véxase que o indefinido ben se pode cuantificar e cualificar de maneira máis concisa que a perífrase xa que, ademais de se localizar nun tempo amplo, na primeira pódense predicar circunstanciais que non admite a segunda das formas.

(54) Despois de chegares tocamos tres pezas e marchamos.

(55) *Despois de chegares temos tocado tres pezas e marchamos. 
E logo, cando usamos indistintamente o pretérito e a perífrase para referirnos a acontecementos habituais, cal é a diferenza desde a percepción do acto? Vexamos estes dous exemplos:

(56) Non o atopei pola rúa.

(57) Endexamais o atopei pola rúa.

No primeiro exemplo (56), podemos dicir que a percepción se dá na confluencia da negación co verbo nunha única acción: non + atopar; se ben no segundo exemplo (57) a situación é habitual no transcurso do tempo desde o pasado até o presente: $($ non + atopar $)+($ non + atopar $)+($ non + atopar $)+\ldots$ Segundo a nosa consideración perceptiva, isto non funciona da mesma maneira cando usamos a perífrase, por dúas razóns:

Primeiro, cando a oración vai en negativo, a iteratividade non funciona como tal, neutralizándose:

(58) Non o teño atopado pola rúa $\neq$ (non + teño atopado $)+($ non + teño atopado $)+\ldots$; mais si, $($ non + atopar $)+($ non + atopar $)+\ldots ;$

polo que estas dúas formas quedan neutralizadas na negación, igualándose en non + atopar, unha única volta.

Segundo, porque cando a oración é afirmativa, desde a percepción acontece que:

(59) Téñoo atopado pola rúa $=$ atopeino + atopeino + atopeino $+\ldots \neq($ ter + atopar $)+($ ter + atopar $)+\ldots$,

sumatorio, este último, que daría unha cantidade infinita de accións que non sería posíbel na vida real.

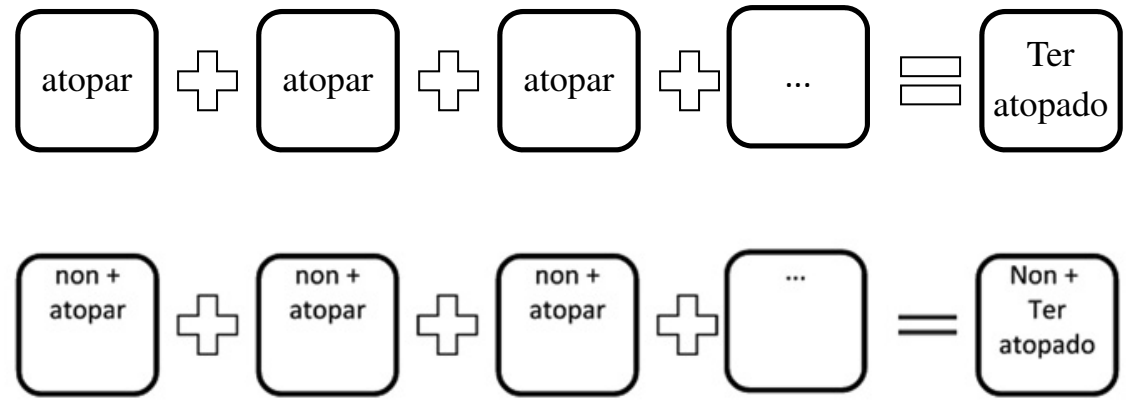

Polo que resulta que a figura será a perfectividade, como terminación do feito, á semellanza do resto do paradigma dos tempos compostos sinalados 
anteriormente; mentres que a iteratividade pasará ao segundo plano da percepción, é dicir ao fondo.

Fica demostrada a nosa análise da percepción remota da forma perifrástica como termo principal de uso (figura) na lingua, que non vén dada pola súa maior ou menor iteratividade (fondo). E dicir, que o importante non é que teña acaecido unha cantidade concreta, en máis dunha ocasión, do feito, senón que este feito se perciba como distante no tempo, fóra do espazo temporal da nosa percepción dos feitos valorados como actuais.

\section{CONCLUSIÓN}

Tense teorizado, e continúa a se teorizar afervoadamente, sobre os paradigmas verbais e o seu estado dentro da lingua e das falas reais. O tema da para moito, sen dúbida. A pretensión deste artigo xorde froito da convicción de que a lingua ben pode seres explicada polo pensamento. Adoitamos escoitar as teorías, sen dúbida de grande achega lingüística, que hoxe en día están máis en voga, dado ao avance nos estudos que a lingüística comparte con outras ciencias máis ou menos afíns, véxase a computación, a clínica, etcétera. Cremos que a lingua, cara ao reforzamento da nosa identidade e da identidade da nosa fala, tamén ten que seguir o camiño do estudo humanístico, aínda, afortunadamente, non pechado.

A lei «figura-fondo» como fundamento de percepción ofrécenos unha boa ferramenta de análise dos nosos usos verbais. A vista do contido, non resulta ilóxico pensar que se nós, viventes, estamos encadeados ao presente físico; nós, falantes, estamos mesmamente forzados a un uso da lingua desde ese propio presente; e nós, lingüistas, a unha valoración desa realidade perceptiva desde ese presente actual. $\mathrm{O}$ fundamento do traballo baséase nesa actualidade dos feitos. Así, o pasado, non deixa de ser un recordo ou unha evocación desde o presente; ao mesmo tempo, é unha percepción remota do que foi un presente real. De aí que para nós o pretérito galego na forma «fun» non é, se non, un presente lembrado, en tempo e espazo; mentres que «teño ido» evoca feitos afastándose dese presente lembrado por non posuír tempo e espazo concreto. O futuro, polas súas características especiais de feitos aínda non acaecidos, non é máis que unha evidencialidade das nosas intencións ou propósitos ou unha procura dos desexos actuais. Por iso, o seu estudo perceptivo faise, asemade, desde a actualidade, como un tempo presente intencional. Acontece, polo tanto, que a temporalidade verbal se esgota nunha marisma de modos e aspectos; de recordos e intencións. Viría ao caso facer unha táboa dos usos verbais a partires deste tratado de percepción, máis reflectimos aquí unha primeira catalogación á vista do considerado ao longo do estudo, tendo en conta que canto ao estudo das formas do subxuntivo, contemplamos só aqueles verbos ou formas que teñen relación directa coa temporalidade ou que incidían na conxunción ou delimitación doutros modos verbais: 

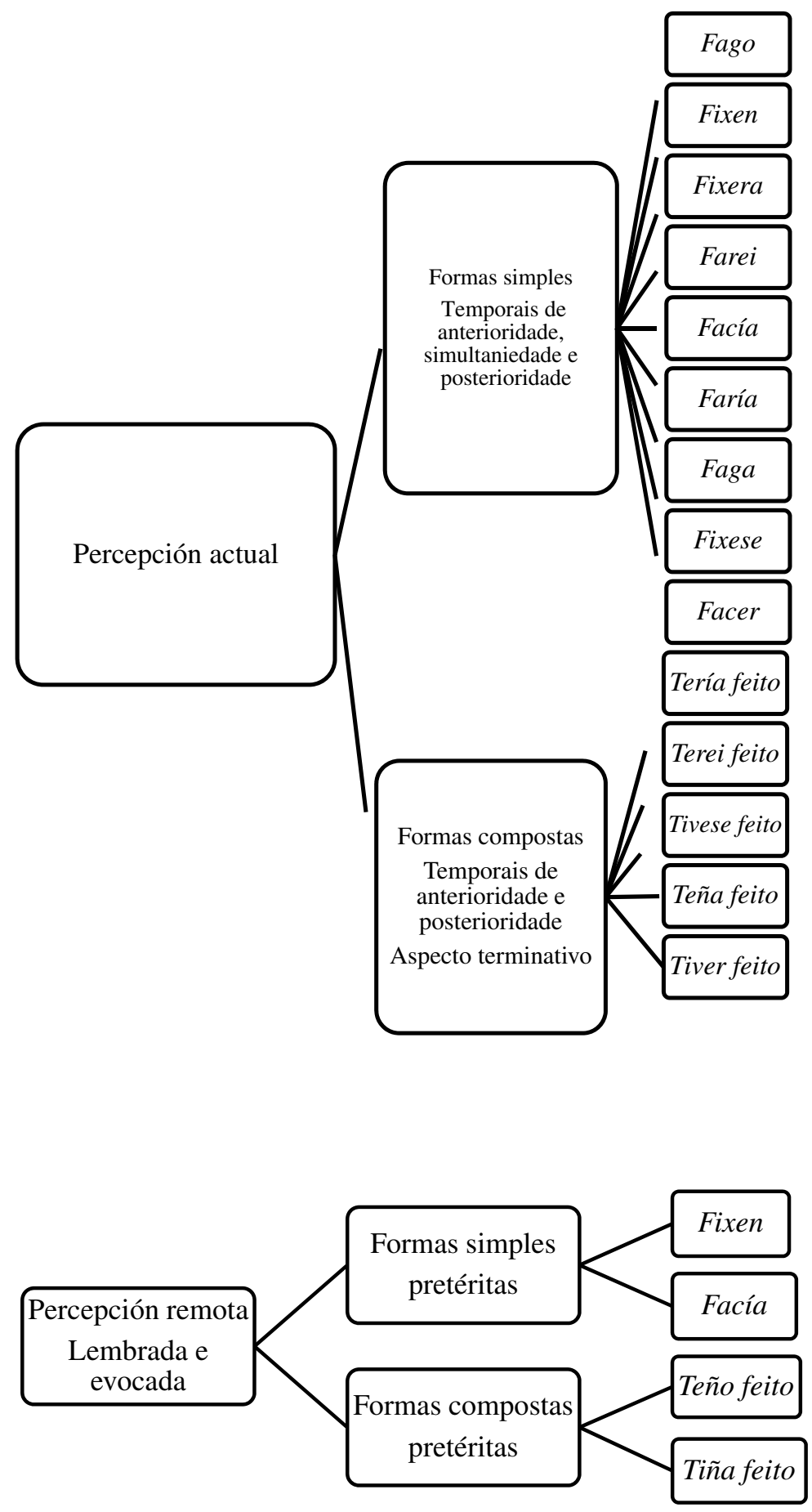
O estudo introduce, a máis, os tempos compostos que na realidade se veñen usando. Este é un tema polémico por canto non están recollidos na oficialidade normativa da lingua. Á vista dos datos que recollemos de fontes reais, é dicir, da riqueza lexical que a literatura e a escritura xornalística nos ofrecen, non podemos negar a existencia dos tempos compostos no galego actual, que como se pode observar (anexo I) non son coincidentes coa totalidade do paradigma dos tempos en español, así como tampouco dos seus referentes nun idioma irmán, histórica e xeograficamente, como é o portugués.

O uso da lingua é o que é polos seus falantes, este debe de ser observado, recolleito e estudado, pero en ningún caso restrinxido.

\section{BIBLIOGRAFÍA}

\section{De consulta}

Benveniste, E. (1989) Problemas de lingüística general. Pontes, Campinas, S. P.

Bosque et al. (2009) Nueva Gramática de la Lengua española. Madrid, Espasa Libros, S. L. U.

Caamaño, I.-A. (1981) Unha alternativa gandeira pra os montes da Galiza. Vigo, Galaxia.

Carballo, R. (1996) Gramática elemental del gallego común. Vigo, Galaxia, S. A.

Carrasco, Á. (2008) Tiempos compuestos y formas verbales compuestas. Madrid, Iberoamericana editorial Vervuert.

Carré, L. (1919) Compendio de gramática galega. A Coruña, Real Academia Galega.

Carreira, A. (1998) Filosofía da Ciencia e da Tecnoloxía. A Coruña, Bahía Edicións.

De Toro, S. (1993) Tic tac. Santiago de Compostela, A Nosa Terra edicións.

Dominguez, X. (2008) O galego. Vigo, Ir indo edicións.

Escandell, M. V. (2010) Futuro y Evidencialidad. Anuario de Lingüística Hispánica, XXVI. Universidad de Valladolid., 9-34.

Fernández, B. (2000) Os rudimentos da lingüística galega. Santiago de Compostela, Verba, anuario galego de filoloxía.

Férnandez, X. (1975) A morte de Frank González. La Coruña, Ediciones do Castro. 
Freixeiro, X. R. (2000) Gramática da lingua galega. Vigo, A Nosa Terra, S. A.

Frías, X. (2010) Compendio de gramática galega. Revista Philologica romanica, suplemento 9.

- (2012). Some notes about galician verb. Ianua. Revista Philologica Romanica.

García-Sabadell, D. (1976). As facianas do erotismo contemporáneo. Santiago de Compostela, Galaxia.

Gutierrez Araus, M. L. (2004) Problemas fundamentales de la gramática del español como 2/L. Madrid, Arco Libros.

López García, Á. (1980) Para una Gramátia Liminar. Madrid, Cátedra.

- (1993) Linguistica topologica e percezione visiva. Quaderni di Studio semiotici, 65-78.

- (1994) Categorías y funciones en la percepción de la oración.

- (2002) La formación de palabras como proceso cognitivo. Aspectos de morfología derivativa del español, 79-93.

- (2004) Tres dominios cognitivos y un solo sistema de leyes. Revista Argentina de Lingüística, 16.

- (2005) Gramática cognitiva para profesores de español como L2. Madrid, Arco libros.

- (2006) Lingüística y percepción, categorías y funciones en la percepción de la oración. Dialogía, revista de lingüistica, literatura y cultura, 11-34.

- (s.f.) El contraste de lenguas desde el método cognitivo tipológico.

López, Á. (2005) Gramática cognitiva para profesores de español L2. Madrid, Arco Libros.

Lugris, M. (1931) Gramática do idioma galego. A Coruña, Imprenta Moret.

Maiz, B. (1994) Nautilus 1892-1894. Vigo, Edicións Xerais de Galicia, S. A.

Mirás, F. (1864) Compendio de Gramática gallega-castellana. Santiago, Establecimiento tippográfico de Manuel Mirás.

Moscoso, E. (2000) Os tempos compostos no galego medieval. Santiago de Compostela, Verbo. Universidade de Santiago de Compostela.

Prego, L. (1994) Socioloxía e psicoloxía. Santiago de Compostela, Toxosoutos.

Rúa, M. P. (1996) Galicia Internacional GL1996-03/38. Santiago de Compostela, Soteblán editores. 
Saco, J. A. (1868) Gramática gallega. Lugo, Imprenta de Soto Freire.

Vazquez, M. (1997) Anxos e tempos de chuvias. Vigo, Ed. Xerais de Galicia.

Veyrat Rigat, M. (2002) La categoría verbo, un enfoque perceptivo. Revista electrónica de estudios filológicos, número III.

Vixante, H. (2002) A Nosa Terra, Promocións Culturais S. A., ANT-2002-09$26 / 48$.

Weinrich, H. (1968) Estructura y función en los tiempos del lenguaje. Madrid, Gredos.

\section{De exemplos}

A Nosa Terra. (2007). A Nosa Terra, Promocións culturais de Galicia, ANT2007-02-22/8.

Abuin de Tembra, A. (2000). Xornal. Santiago de Compostela: Editorial Compostela.

Caamaño, I.-A. (1981). Unha alternativa gandeira pra móntesvos dá Galiza. Vigo: Galaxia.

Carreira, A. (1998). Filosofía dá Ciencia e dá Tecnoloxía. A Coruña: Bahía Edicións.

De Toro, S. (1993). Tic tac. Santiago de Compostela: A Nosa Terra edicións.

Maiz, B. (1994). Nautilus 1892-1894. Vigo: Edicións Xerais de Galicia, S. A.

Moure, T. (2005). Outro idioma é posible. Na procura dunha lingua para a humanidade. Vigo: Galaxia.

- (2007). Herba Moura. Vigo: Edicións Xerais de Galicia.

Prego, L. (1994). Socioloxía e psicoloxía. Santiago de Compostela: Toxosoutos.

Rivas, M. (1997). Vos partidos políticos na Galiza. A Voz de Galicia.

Rúa, M. P. (1996). Galicia Internacional GL1996-03/38. Santiago de Compostela: Soteblán editores.

Vazquez, M. (1997). Anxos e tempos de chuvias. Vigo: Ed. Xerais de Galicia.

Veiga, M. (2003). A Nosa Terra, Promocións culturais de Galicia, ANT2003$02-6 / 28$.

Vixante, H. (2002). A Nosa Terra, Promocións Culturais S. A., ANT-2002-09-26/48. 
Anexo I

\begin{tabular}{|l|l|l|}
\hline \multicolumn{3}{|c|}{ Tempos verbais galegos } \\
\hline & \multicolumn{1}{|c|}{ Indicativo } & \multicolumn{1}{c|}{ Subxuntivo } \\
\hline Presente & Fago & Faga \\
\hline $\begin{array}{l}\text { Pretérito Imperfecto } \\
\text { (Copretérito) }\end{array}$ & Facía & Fixese \\
\hline $\begin{array}{l}\text { Pretérito Indefinido } \\
\text { (Pretérito) }\end{array}$ & Fixen & \\
\hline $\begin{array}{l}\text { Pretérito Perfecto } \\
\text { (Antepresente) }\end{array}$ & & Teña feito \\
\hline $\begin{array}{l}\text { Pretérito Pluscuamperfecto } \\
\text { (Antecopretérito) }\end{array}$ & [Fixera] & Tivese feito \\
\hline $\begin{array}{l}\text { Pretérito Anterior } \\
\text { (Antepretérito) }\end{array}$ & Farei & Facer \\
\hline $\begin{array}{l}\text { Futuro Simple } \\
\text { (Simple) }\end{array}$ & Terei feito & Tiver feito \\
\hline $\begin{array}{l}\text { Futuro Perfecto } \\
\text { (Antefuturo) }\end{array}$ & Faría & \\
\hline $\begin{array}{l}\text { Condicional Simple } \\
\text { (Pospretérito) }\end{array}$ & Tería feito & \\
\hline $\begin{array}{l}\text { Condicional perfecto } \\
\text { (Antepospretérito) }\end{array}$ & & \\
\hline
\end{tabular}

